\title{
IMPROVEMENTS IN DESCRIBING WAVE OVERTOPPING PROCESSES
}

\author{
Steven Hughes ${ }^{1}$, Christopher Thornton ${ }^{2}$, Jentsje van der Meer ${ }^{3}$, and Bryon Scholl ${ }^{4}$
}

\begin{abstract}
This paper presents a new empirical relation for the shape factor in the Weibull distribution that describes the distribution of overtopping wave volumes. This improvement increases the applicable range of the Weibull distribution from very low average overtopping discharges to large discharges resulting from combined wave overtopping and steady surge overflow at negative freeboards. The effect this improvement has on wave overtopping simulation is also discussed. Measured maximum flow thicknesses, velocities, and discharges from experiments of combined wave and surge overtopping are examined to learn more about the variability of these key parameters as a function of individual overtopping wave volumes. A key finding is that wave volumes containing the $2 \%$-exceedance value of maximum velocity typically have maximum flow thicknesses well below the $2 \%$-exceedance level, and viceversa. Furthermore, the $2 \%$-exceedance hydrodynamic parameters do not occur in the $2 \%$-exceedance wave volumes. Finally, empirical relationships are developed for several parameters that showed strong trends.
\end{abstract}

Keywords: wave overtopping; overtopping simulators; overtopping wave distribution; overtopping parameters

\section{INTRODUCTION}

The magnitude of wave overtopping is a critical design parameter for determining the crest elevation of dikes, levees, breakwaters, and other structures. Flooding potential is determined from the quantity of overtopping water and storm duration, and a major concern for engineers is damage to the crest and landward-side slopes of earthen flood protection structures by hydrodynamic forces associated with severe wave overtopping. Empirical equations describing wave overtopping processes in terms of incident wave conditions, structure geometry, and crest freeboard have been developed based on small- and large-scale physical model tests of common structure geometries. When wave conditions and freeboard remain relatively constant, wave overtopping can be represented by the mean discharge, $q$, and the distribution of individual overtopping wave volumes, $P_{V}$. However, the hydrodynamic forces exerted on the structure crest and landward-side slope depend largely on the distributions of instantaneous flow thicknesses and flow velocities that occur over the duration of each overtopping wave.

Controlled full-scale testing of dike and levee slope resiliency can be achieved using Wave Overtopping Simulators (Van der Meer, et al. 2006; Van der Meer, et al. 2008) provided the details of wave overtopping hydrodynamics are understood and reasonably approximated. Wave overtopping simulators replicate wave overtopping by releasing individual wave volumes in such a manner that the maximum flow thickness and maximum velocity near the leading edge (tongue) of the released wave volume conform reasonably well to our present understanding of what these two parameters should be for a given overtopping wave volume. As additional data become available from experiments, it is imperative that engineers incorporate the new data into existing data sets in order to improve and refine the empirical relationships needed to conduct reliable simulations of wave overtopping at full scale.

This paper presents a new empirical relation for the shape factor in the Weibull distribution that determines the extreme tail of the wave overtopping volume distribution. This improvement results in a wave overtopping distribution that is more suitable for severe wave overtopping, but still accurately reproduces the distribution for less severe overtopping conditions. The effect this improvement has on wave overtopping simulation is also discussed. Measured maximum flow thicknesses, velocities, and discharges from experiments of combined wave and surge overtopping are examined to learn more about the variability of these key parameters as a function of individual overtopping wave volume.

\section{WAVE OVERTOPPING VOLUME DISTRIBUTION}

\section{Previous Developments}

Van der Meer and Janssen (1995) investigated wave-only overtopping of sloping-front structures, and they found that the distribution of individual overtopping wave volumes was well represented by

\footnotetext{
${ }^{1}$ Engineering Research Center, Colorado State University, 1320 Campus Delivery, Fort Collins, Co 80523, USA.

2 Engineering Research Center, Colorado State University, 1320 Campus Delivery, Fort Collins, CO 80523, USA.

${ }^{3}$ Van der Meer Consulting, BV, P.O. Box 423, 8440 AK Heerenveen, The Netherlands.

${ }^{4}$ Engineering Research Center, Colorado State University, 1320 Campus Delivery, Fort Collins, CO 80523, USA.
} 
the two-parameter Weibull probability distribution give by either Eq. 1 (cumulative probability distribution) or Eq. 2 (percent exceedance distribution).

$$
\begin{aligned}
& P_{V}\left(V_{i} \leq V\right)=1-\exp \left[-\left(\frac{V}{a}\right)^{b}\right] \\
& P_{V \%}\left(V_{i} \geq V\right)=\exp \left[-\left(\frac{V}{a}\right)^{b}\right] \cdot(100 \%)
\end{aligned}
$$

where $P_{V}$ is the probability that an individual wave volume $\left(V_{i}\right)$ will be less than a specified volume $(V)$, and $P_{V \%}$ is the percentage of wave volumes that will exceed the specified volume $(V)$. The two parameters of the Weibull distribution are the non-dimensional shape factor, $b$, that helps define the extreme tail of the distribution and the dimensional scale factor, $a$, that normalizes the distribution. Van der Meer and Janssen (1995) formulated the scale factor as

$$
a=\left(\frac{1}{\Gamma(1+1 / b)}\right) \cdot\left(\frac{q T_{m}}{P_{o v}}\right)
$$

where $q$ is the average wave overtopping discharge, $T_{m}$ is the mean wave period, $P_{o v}$ is the probability of overtopping waves for a given condition (number of overtopping waves divided by total incident waves), and $\Gamma$ is the mathematical gamma function. Van der Meer and Janssen fit the Weibull distribution to 14 sets of overtopping measurements acquired for mild seaward slopes (1:3 and 1:4) spanning a range of $0.99<R_{c} / H_{m 0}<3.16$, where $R_{c}$ is structure freeboard and $H_{m 0}$ is the incident energy-based significant wave height. These values of relative freeboard represent low to moderate wave overtopping conditions. They found a constant shape factor of $b=0.75$ that gave a corresponding scale factor of

$$
a=0.84 \cdot\left(\frac{q T_{m}}{P_{o v}}\right)
$$

Van der Meer (2010) modified Eq. 4 to better represent situations with a low number of overtopping waves, i.e.,

$$
a=\left[0.84+1.2\left(N_{o w}\right)^{-0.8}\right] \cdot\left(\frac{q T_{m}}{P_{o v}}\right)
$$

where $N_{\text {ow }}$ is the number of overtopping waves during the event given by the equation

$$
N_{o w}=N_{w} \cdot P_{o v}=N_{w} \cdot \exp \left[-\left(\sqrt{-\ln 0.02} \frac{R_{c}}{R_{u 2 \%}}\right)^{2}\right]
$$

with $R_{u 2 \%}$ representing the elevation exceeded by $2 \%$ of the wave run-ups on the seaward slope.

More recently Victor (2012) and Victor, et al. (2010) conducted and examined 364 tests for steeper seaward slopes (1:0.36 to 1:2.75) spanning a range of relative freeboard $0.11<R_{c} / H_{m 0}<1.69$. These conditions represented heavier overtopping on steep seaward slopes. They fit the Weibull distribution to the upper $50 \%$ of the volumes, and their analysis determined that the Weibull shape factor varied as a function of relative freeboard and seaward slope as

$$
b=\exp \left(-2.0 \frac{R_{c}}{H_{m 0}}\right)+(0.56+0.15 \cot \alpha)
$$

with the scale factor given by Eq. 3 using $b$ from Eq. 7. Victor (2012) gave an approximation of the scale factor, i.e., 


$$
a=1.13 \tanh (1.32 b) \cdot\left(\frac{q T_{m}}{P_{o v}}\right)
$$

\section{Improvement of the Overtopping Wave Volume Distribution}

Hughes and Nadal (2009) conducted 27 small-scale laboratory experiments of combined wave overtopping and surge overflow for cases with negative relative freeboards $-0.1<R_{c} / H_{m 0}<-2.0$ with a seaward slope of 1:4.25. They had fit a Weibull distribution to all the overtopping wave volumes and proposed empirical relationships for $a$ and $b$. The individual wave volume data were re-analyzed for this paper using various percentages of the upper values to determine a better Weibull fit to the extreme values. It was concluded that the best fit to the extreme tail of the wave volume distribution was obtained using the upper $10 \%$ of the values. Figure 1 illustrates a best-fit to one of the experiments using the upper $50 \%$ of the values (upper plot) and the upper $10 \%$ of the values (lower plot).
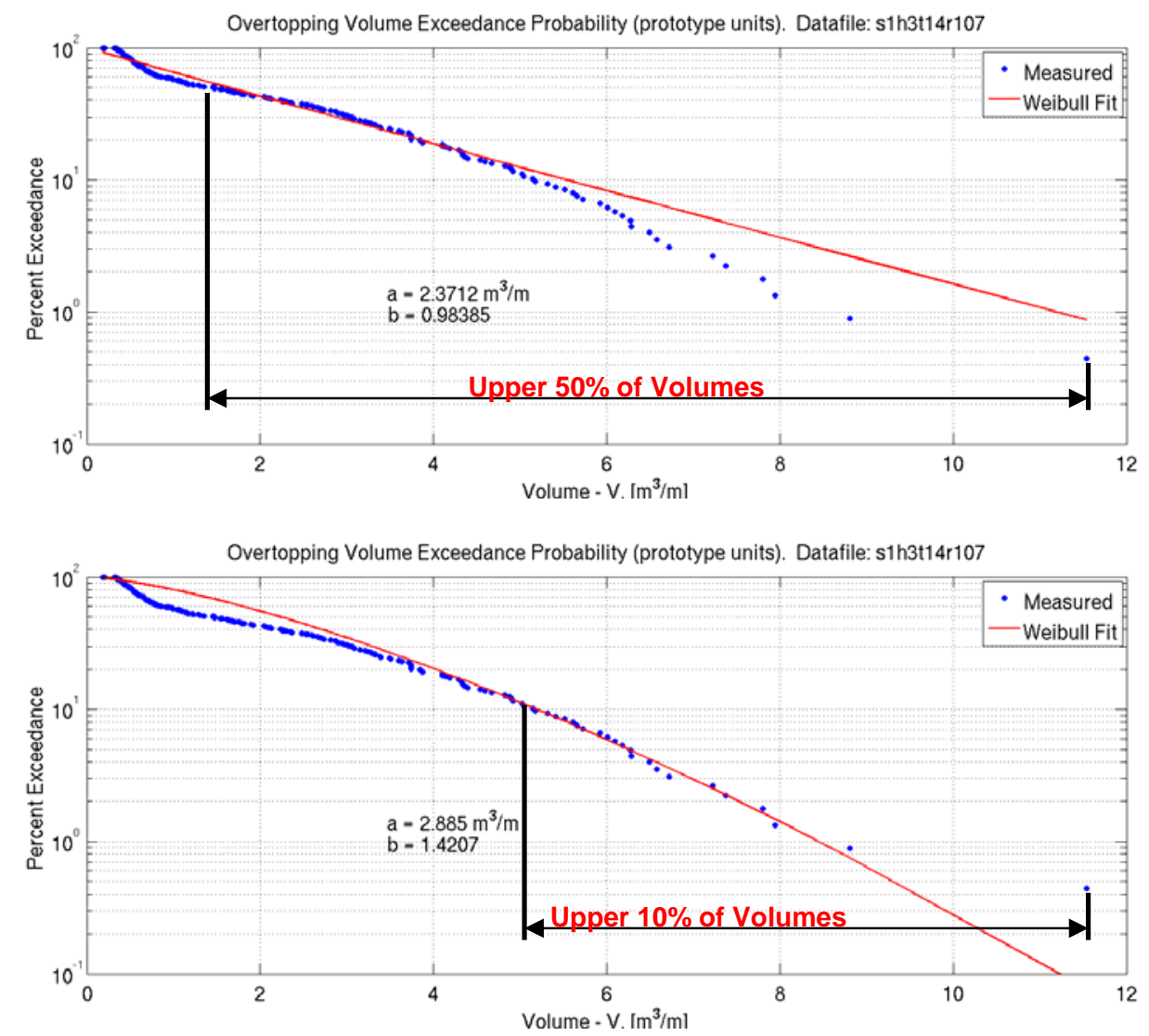

Figure 1. Best-fit of Weibull distribution to combined wave and surge overtopping data.

Fitting the Weibull distribution to the upper $10 \%$ of individual wave volumes gave better representation of the extreme values while sacrificing accuracy in the lower volume range of the distribution. This was considered acceptable because the operational range of wave overtopping simulators is linked to the larger waves in the distribution.

The 27 best-fit values of Weibull shape factor from the Hughes and Nadal (2009) combined wave and surge overtopping experiments were added to the 14 wave-only overtopping shape factors of Van der Meer and Janssen (1995) and the 364 values of Victor, et al. (2012) and plotted versus relative freeboard. The data are shown in Fig. 2. The dashed line is Victor, et al.'s (2012) equation given by Eq. 7 with a seaward slope of 1:4. Equation 7 is being applied well outside the range of steep slopes on which it is based, and it over-predicts the shape factor for all the data points. However, for steep slopes and low relative freeboard, the Victor, et al. equation is preferred.

The solid line in Fig. 2 is an empirical fit to the shape factor data given by the expression 


$$
b=\left[\exp \left(-0.6 \frac{R_{c}}{H_{m 0}}\right)\right]^{1.8}+0.64
$$

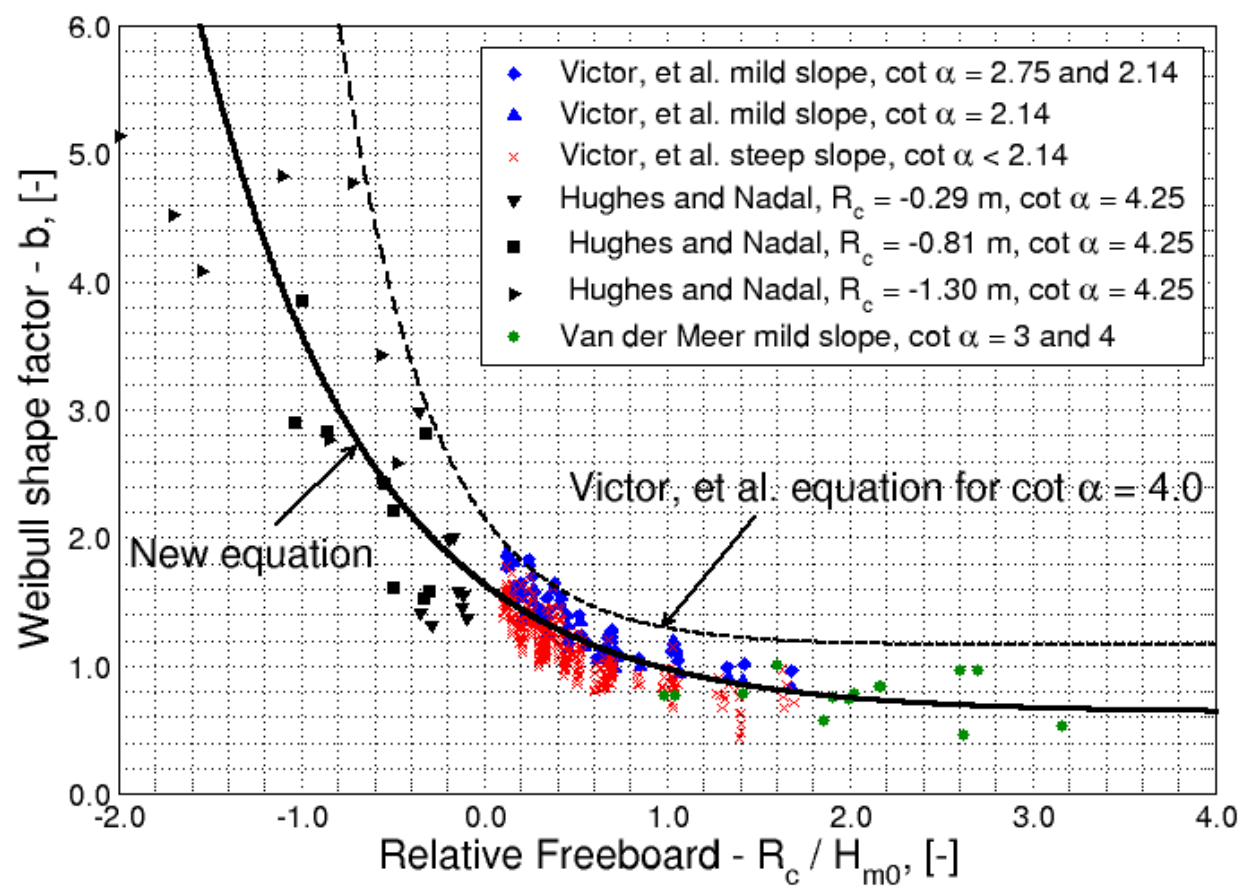

Figure 2. New Weibull shape factor, $b$, spanning a large range of relative freeboard.

There is no physical significance to the form of Eq. 9 other than the fact that it represents the entire range of relative freeboard reasonably well, including the original data of Van der Meer and Janssen (1995). Also, Eq. 9 does not depend on the seaward slope angle despite the range of slope angles represented in the data.

\section{IMPACT ON WAVE OVERTOPPING SIMULATION}

Capability of wave overtopping simulators is limited by the maximum wave volume required for a given set of overtopping conditions. A tentative estimate of the maximum wave volume in the Weibull distribution was given by Van der Meer and Janssen (1995) as

$$
\left(V_{\max }\right)=a \cdot\left[\ln \left(N_{o w}\right)\right]^{1 / b}
$$

where $N_{o w}$ is the number of overtopping waves estimated by Eq. 6 .

Victor, et al. (2012) noted that larger values of the Weibull shape factor, $b$, result in relatively smaller maximum wave volumes. Therefore, overtopping conditions having $R_{c} / H_{m 0}<2.0$ will have shape factors greater than $b=0.75$; and the estimated maximum wave volume required for wave overtopping simulation will be less than required by the original wave volume distribution. For example, the solid line in Fig. 3 is the theoretical wave volume distribution required for an average overtopping discharge of $q=370 \mathrm{l} / \mathrm{s}$ per $\mathrm{m}$ using the original formulation with a constant value of $b=$ 0.75 . The maximum required wave volume is $32.4 \mathrm{~m}^{3} / \mathrm{m}$, but the maximum capacity of the wave overtopping simulator at Colorado State University is $15.8 \mathrm{~m}^{3} / \mathrm{m}$. This overtopping condition was approximated by adding additional wave volumes at the simulator maximum to compensate for the inability to generate the theoretical maximum volumes. The compromise is shown by the hatched area in Fig. 3. 


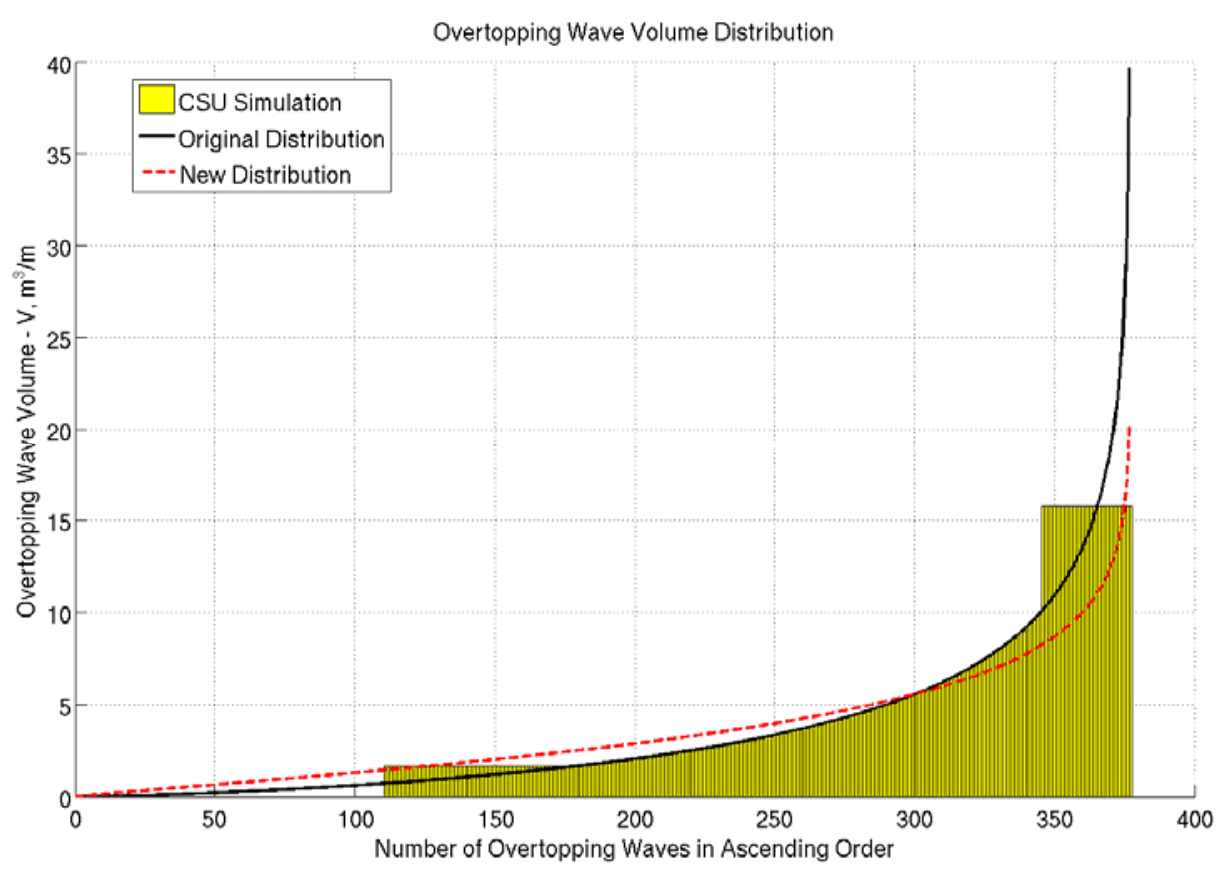

Figure 3. Wave overtopping distribution for simulating $q=370 \mathrm{l} / \mathrm{s}$ per $\mathrm{m}$.

The dashed line in Fig. 3 shows the new wave volume distribution with scale and shape factors given by Eq. 3 and 9, respectively. The theoretical maximum wave volume for the new distribution is $17.8 \mathrm{~m} 3 / \mathrm{m}$, so this particular overtopping condition can now be simulated with much less compromise.

The ratio of the theoretical maximum wave volume calculated using the original distribution (Van der Meer's scale factor from Eq. 5 and $b=0.75)$ to the theoretical maximum wave volume using the new distribution (scale factor given by Eq. 3 and shape factor by Eq. 9) is expressed as

$$
\frac{\left(V_{\max }\right)_{\text {Orig }}}{\left(V_{\max }\right)_{\text {New }}}=\left[\Gamma\left(1+\frac{1}{b}\right)\right] \cdot\left[0.84+1.2\left(N_{o w}\right)^{-0.8}\right] \cdot\left[\ln \left(N_{o w}\right)\right]^{(1 / 0.75-1 / b)}
$$

Equation 11 is plotted in Fig. 4 for various numbers of overtopping waves and for a specific value of Iribarren number, $\xi_{m-1,0}=1.5$. The CSU simulation depicted in Fig. 3 is indicated by the circle at $R_{c}$ $/ H_{m 0}=0.65$. Thus, the new empirical expression for shape factor (Eq. 9) means that wave overtopping simulators can replicate without compromise larger overtopping conditions than previously because the constraint of the largest required wave volume has been reduced, particularly at lower values of relative freeboard.

\section{INDIVIDUAL WAVE VOLUME PARAMETERS}

In addition to reproducing the distribution of individual overtopping wave volumes and the average overtopping discharge, another important goal of wave overtopping simulation is to approximate, to the extent possible, the hydraulic flow parameters associated with individual overtopping wave volumes. Of particular importance are the maximum flow thickness $\left(h_{\max }\right)$, maximum velocity $\left(U_{\max }\right)$, and maximum discharge $\left(q_{\max }=\right.$ velocity $\mathrm{x}$ thickness $)$ at the leading edge of the wave, and the duration of overtopping $\left(T_{o}\right)$ associated with each volume. These parameters are defined in Fig. 5.

Measured time series of flow thickness and flow velocity on the crest from the small-scale experiments of Hughes and Nadal (2009) were analyzed in an attempt to better describe the individual wave volume parameters. The analyses of the combined wave and surge overtopping experiments were restricted to the nine tests with the lowest surge overflow (prototype equivalent of $R_{c}=-0.29 \mathrm{~m}$ ). The combined overtopping cases represent an extreme edge of the wave overtopping regime, so it was hoped that limiting the analyses to the lowest negative freeboard case might better correspond to similar analyses of wave-only overtopping. During overtopping with low negative freeboard, the levee 
crest and landward-side slope usually go "dry" between waves. However, every wave does overtop the levee structure.

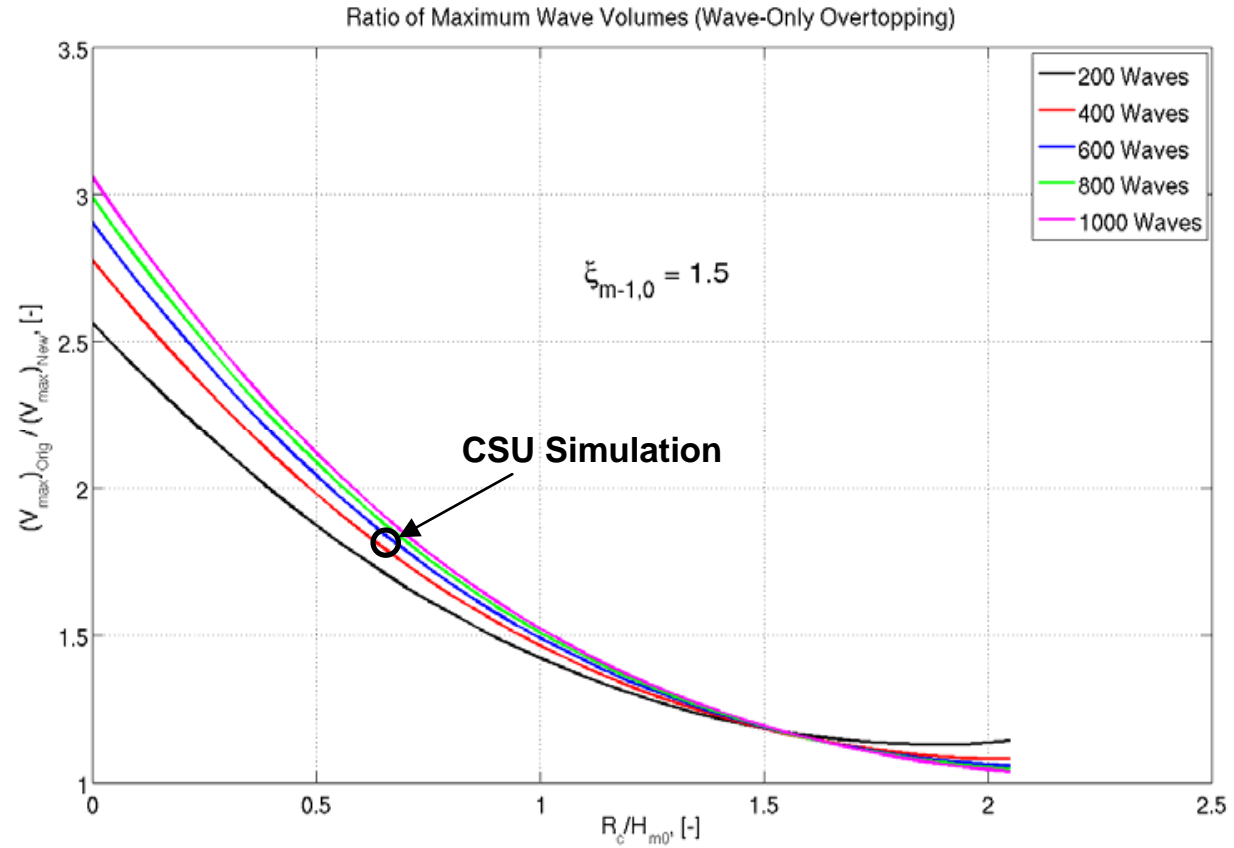

Figure 4. Ratio of maximum wave volumes required for wave overtopping simulation.
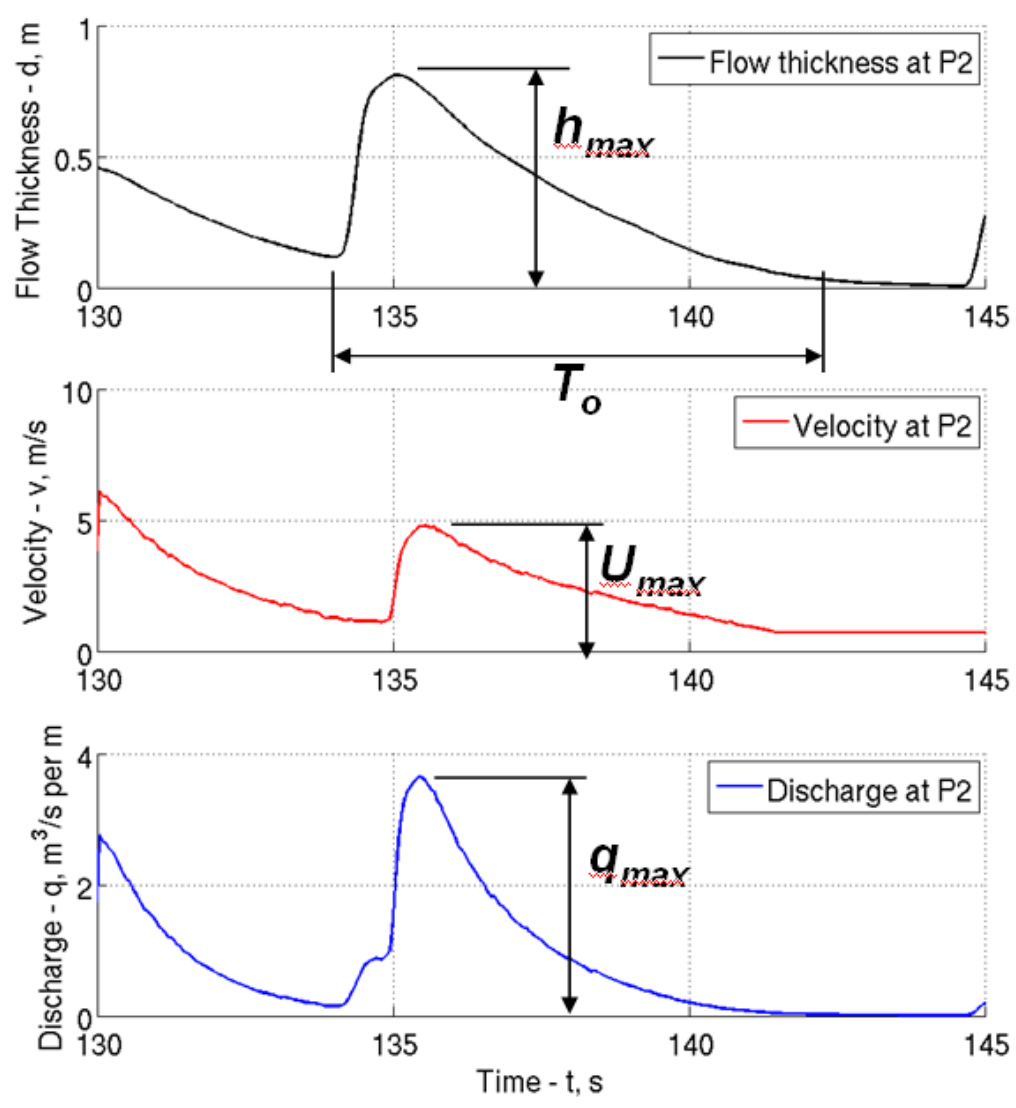

Figure 5. Individual wave volume parameter definitions. 
Figure 6 presents scatter plots from one experiment containing 226 individual overtopping wave volumes. In most of the plots the parameter of interest is plotted against the corresponding wave volume, and trends are evident for $U_{\max }$ vs. $V, q_{\max }$ vs. $V$, and $T_{o}$ vs. $V$. Lesser trend is shown for $h_{\max }$ vs. $V$, and there is a distinct lack of trend for $U_{\max }$ vs. $h_{\max }$ (upper-right plot in Fig. 6).
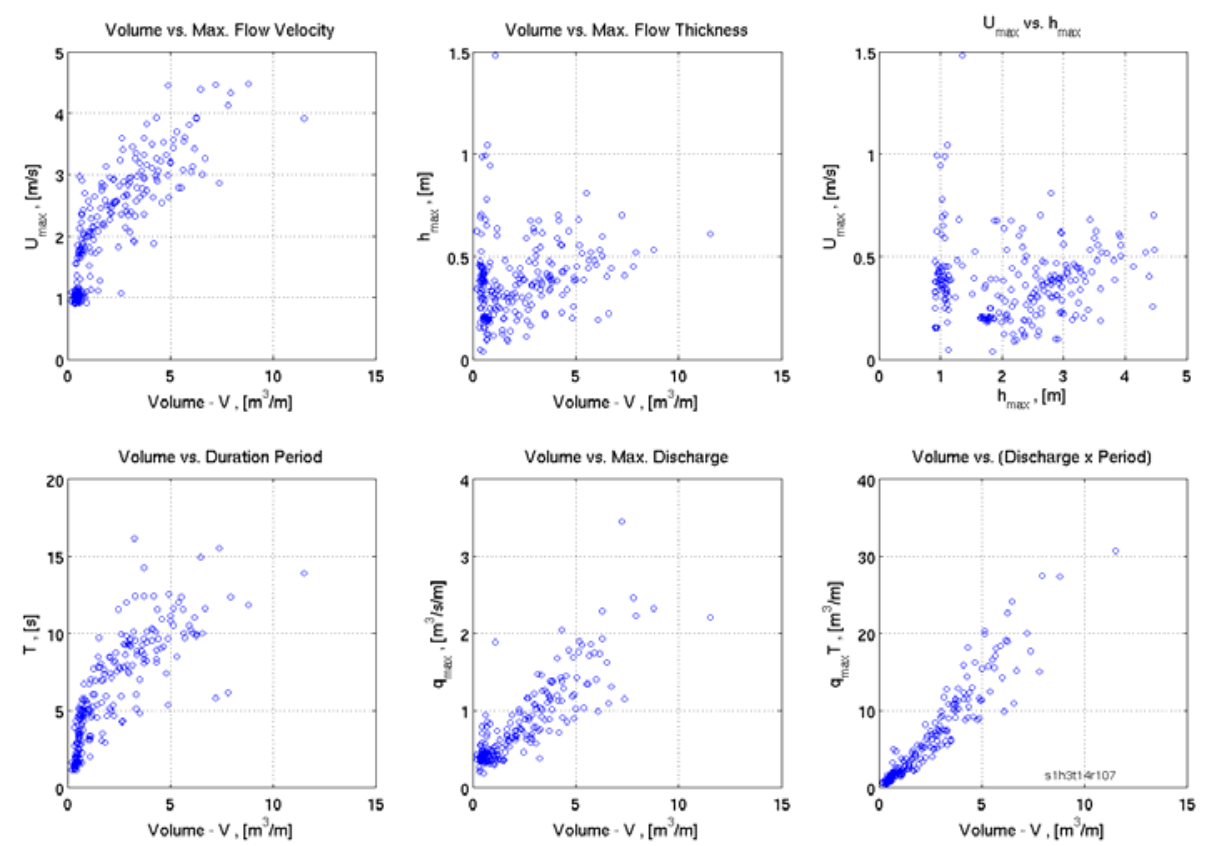

Figure 6. Individual wave volume parameters from an experiment with 226 waves.

\section{Representing Parameters with a Raleigh Distribution}

Van der Meer, et al. (2010) questioned whether the distribution of individual wave volume parameters were actually Rayleigh distributed. To test the Rayleigh hypothesis, parameters from each experiment were rank-ordered; and the Weibull distribution was fit to the upper $10 \%$ of the values to determine the Weibull shape factor, $b$. Shape factors equal to 2 correspond to a Rayleigh distribution. Fig. 7 presents best-fit shape factors as a function of relative freeboard for each of the wave volume parameters. The horizontal line indicates the Rayleigh distribution.

Six of the shape factors found for the parameter $U_{\max }$ had values near $b=2$. The three tests with larger shape factors had the lowest wave heights, and it is speculated that the steady overflow was dominating the maximum velocities in the overtopping waves for these cases. Maximum flow thickness and maximum discharge were clustered about $b=2$, indicating the Rayleigh distribution is perhaps a reasonable assumption for these parameters. However, shape factors for overtopping duration were uniformly greater than $b=2$, which implies that durations cannot be approximated well by a Rayleigh distribution. Similar Weibull fits using the entire rank-ordered values rather than the upper $10 \%$ showed more scatter and less conformance to the Rayleigh distribution. Interest lies in the extreme values of the wave volume parameters, so it was concluded that using the upper $10 \%$ of the values was warranted. 

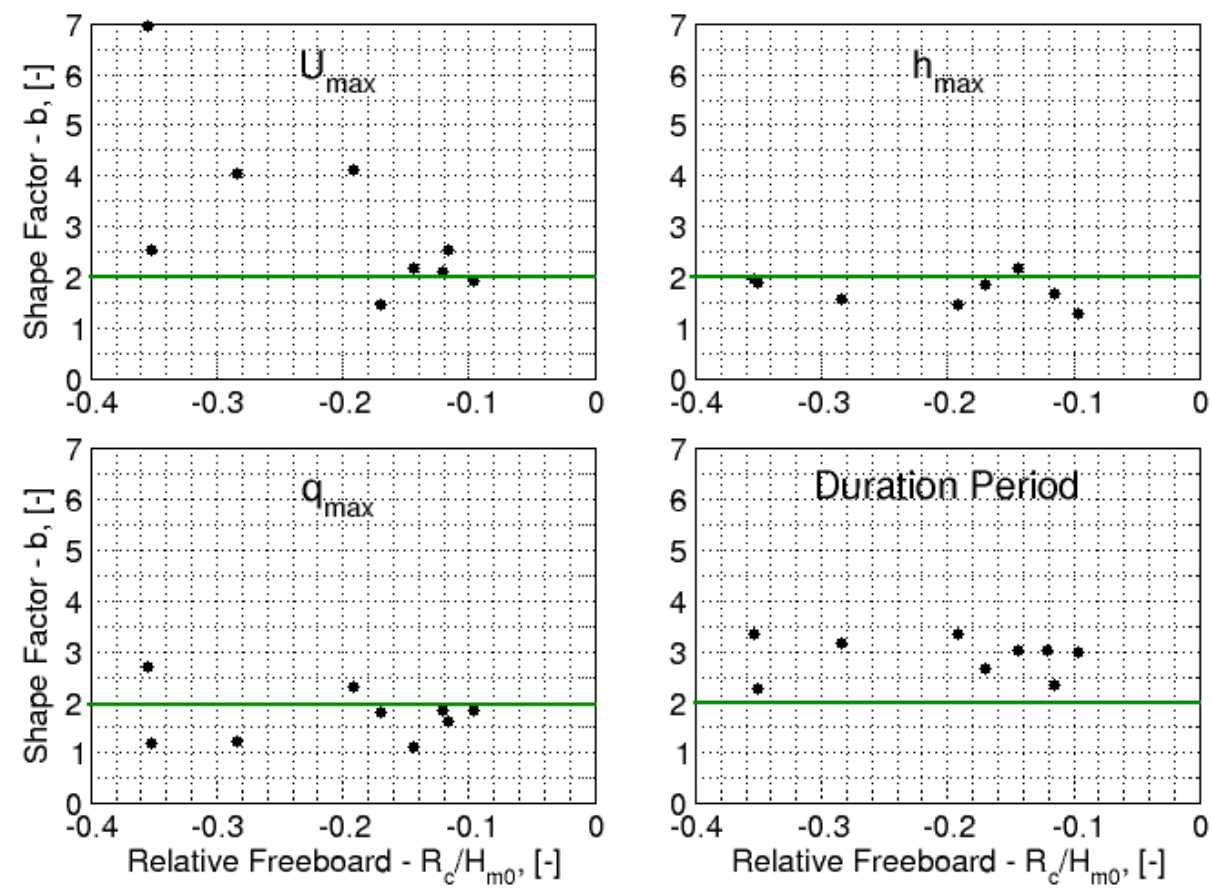

Figure 7. Weibull distribution shape factors for individual wave volume parameters.

\section{Characterization of the 2\% Exceedance Parameters}

Earlier experiments (Schüttrumpf, et al., 2002; Schüttrumpf and Oumeraci, 2005; and Van Gent, 2002) yielded empirical expressions for the maximum individual wave flow thickness $\left(h_{2 \%}\right)$ and maximum velocity $\left(U_{2} \%\right)$ exceeded by only $2 \%$ of the overtopping wave maximum values. These $2 \%$ exceedance parameters were related to incident wave conditions and dike freeboard. Van der Meer, et al. (2010) combined the earlier data with additional data from the small-scale Flowdike experiments (Lorke, et al. 2010a, 2010b), and a re-analysis of the data provided revised equations for the $2 \%$ exceedance maximum flow thickness and $2 \%$-exceedance maximum velocity on the crest of a smooth dike, i.e.,

$$
\begin{gathered}
h_{2 \%}=0.13\left(R_{u 2 \%}-R_{c}\right) \\
U_{2 \%}=0.35 \cot \alpha\left[g\left(R_{u 2 \%}-R_{c}\right)\right]^{1 / 2}
\end{gathered}
$$

where $\alpha$ is the seaward-side slope angle, and $g$ is gravitational acceleration. If indeed $h_{\max }$ and $U_{\max }$ are Rayleigh distributed, then the entire distribution of these two parameters can be estimated from the $2 \%$ values. Combining Eqs. 12 and 13 yields

$$
U_{2 \%}=0.97 \cot \alpha\left(g h_{2 \%}\right)^{1 / 2}
$$

suggesting that a relationship exists between $h_{2 \%}$ and $U_{2 \%}$.

Individual overtopping wave parameters from the nine combined wave and surge overtopping experiments were examined to explore the relationship between maximum flow thickness and maximum velocity. From the rank-ordered lists of each of the parameters, the $2 \%$-exceedance values were determined, and the corresponding values of the other parameters were extracted from the same 
wave volume. For example, for the wave volume containing $h_{2 \%}$ for an experiment, the corresponding values of $U_{\max }$ and $q_{\max }$ were extracted. Likewise, for the wave volume containing $U_{2 \%}$ for an experiment, the corresponding values of $h_{\max }$ and $q_{\max }$ were extracted. Also, the values of $h_{\max }$ and $U_{\max }$ were taken from the $2 \%$-exceedance wave volumes. Scatter plots of extracted values showed little trend when plotted against wave volume.

Perhaps the most interesting aspect of the $2 \%$-exceedance values came from plotting the $h_{2 \%}$ value versus the associated $U_{\max }$ from the same wave volume and the $U_{2 \%}$ value versus the associated $h_{\max }$ from the same wave volume. Fig. 8 is a scatter plot showing pairs of $h_{\max }$ and $U_{\max }$ values from just under 2,100 individual waves from all nine experiments. Overlain on the scatter are values of $U_{2 \%}$ versus associated $h_{\max }$ and values of $h_{2 \%}$ versus associated $U_{\max }$.

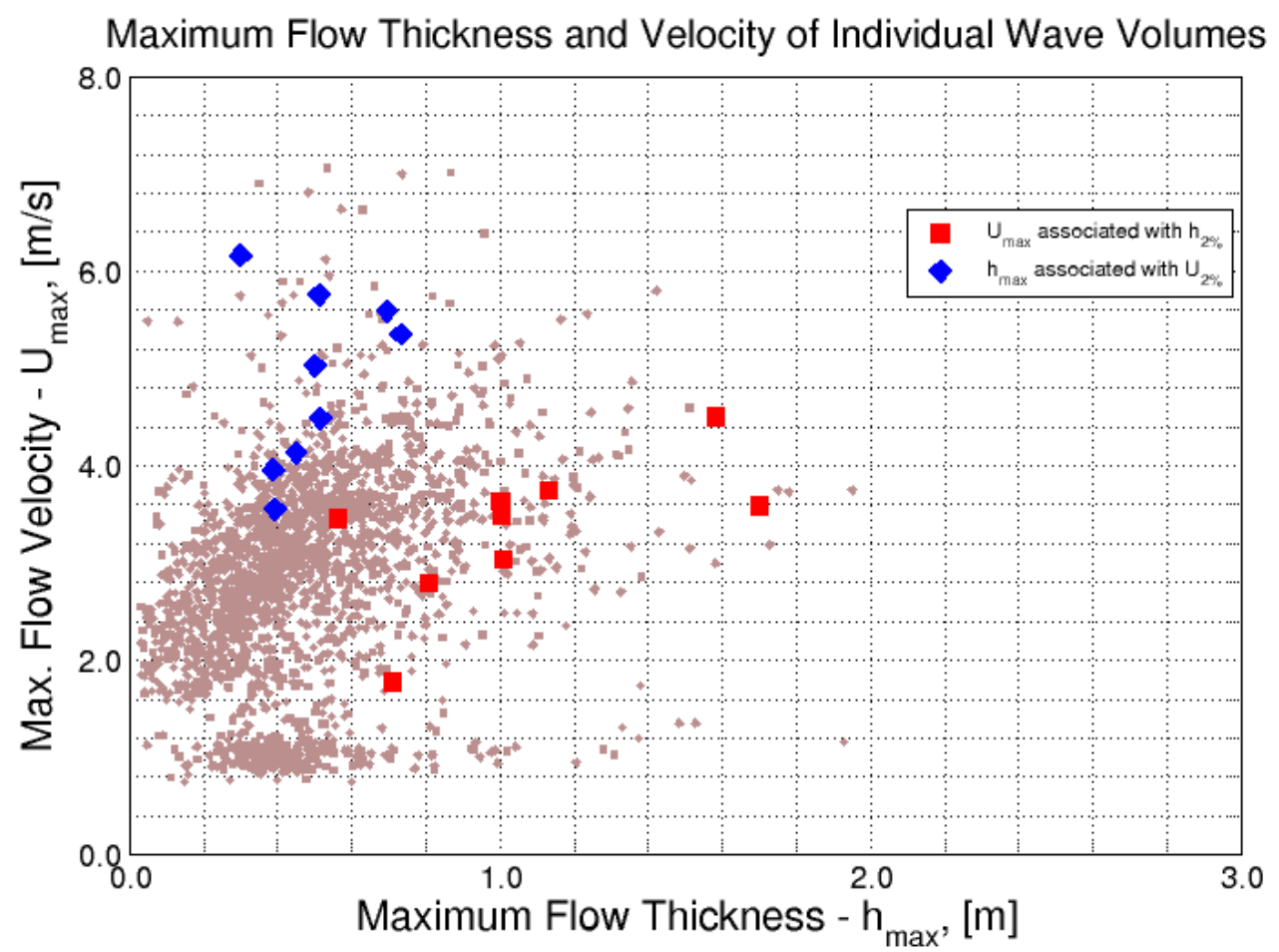

Figure 8. Maximum flow thickness versus maximum velocity for individual wave volumes.

The nine data points represented by the larger squares show that maximum velocities $\left(U_{\max }\right)$ associated with $h_{2 \%}$ are well below typical values of $U_{2 \%}$. Conversely, the data points represented by the large diamonds show that maximum flow thicknesses $\left(h_{\max }\right)$ associated with $U_{2 \%}$ are well below typical values of $h_{2 \%}$. In other words, there is no reason to expect that $2 \%$-exceedance values of flow thickness and velocity will occur in the same wave volume. This complicates specifying appropriate maximum velocity and flow thickness for individual wave volumes when simulating wave overtopping.

Interestingly, when values of $h_{2 \%}$ are plotted versus values of $U_{2 \%}$ from the same experiment (but from different wave volumes); a definite trend is evident as shown by the large dots in Fig. 9. A fit to the nine data pairs in Fig. 9 is given by the equation

$$
U_{2 \%}=1.53\left(g h_{2 \%}\right)^{1 / 2}
$$

which has the same form as the derived Eq. 14. For the 1:4.25 seaward-side slope used in the Hughes and Nadal experiments, the coefficient in Eq. 14 is 4.12, or 2.7 times greater than the coefficient in Eq. 15. Equation 15 was obtained from measurements at the landward side of the levee, whereas the velocity represented in Eq. 14 was acquired at the seaward edge of the dike crest. There could be some 
velocity reduction across the levee crest, but not nearly enough to make up the difference in coefficients. The difference in coefficients may be due to the influence of the steady surge overflow in the Hughes and Nadal experiments, or the decreased importance of seaward-side slope for negative freeboards. Additional data and analyses are needed to better understand the $2 \%$-exceedance wave volume parameters.

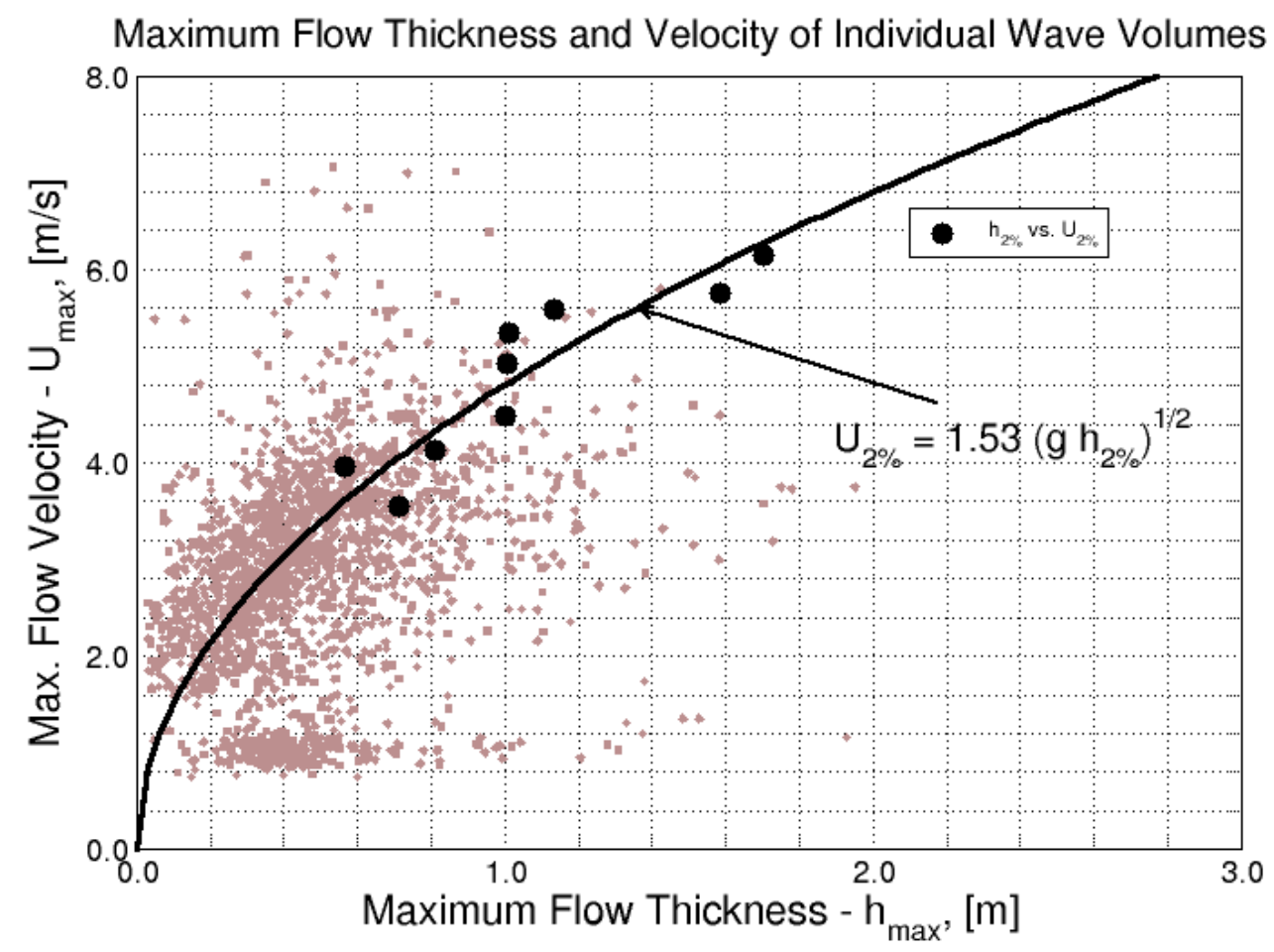

Figure 9. Values of $h_{2 \%}$ versus $U_{2 \%}$ from the same experiment, but different wave volumes.

\section{Maximum Instantaneous Discharge for Individual Overtopping Waves}

All of the scatter plots of individual wave maximum parameters versus wave volume showed varying degrees of correlation, but the best correspondence was seen for the maximum discharge $\left(q_{\max }\right)$ versus individual wave volume as seen in Fig. 10. A best-fit of a dimensionally homogeneous equation with one free parameter to the almost 2,100 data points resulted in

$$
q_{\max }=0.184 \sqrt{g} V^{3 / 4}
$$

where $V$ is the individual wave volume per unit length of levee (e.g., units of $\mathrm{m}^{3} / \mathrm{m}$ ). Equation 16 is shown as the solid line on Fig. 10.

One possible use for a $q_{\max }$ vs. $V$ relationship such as Eq. 16 might be to operate a wave overtopping simulator by assuring that each wave has the correct $q_{\max }$ near the leading edge. However, many combinations of flow thickness and velocity can give the same maximum discharge; and this would mean that the leading edge velocity would most likely be incorrect. An incorrect leading edge velocity would give incorrect shear stresses acting on the levee surface while the flow is still accelerating down the landward-side slope. After terminal velocity is reached farther down the slope, there possibly would be lesser effect caused by an incorrect initial velocity. More work is needed to develop this concept. 


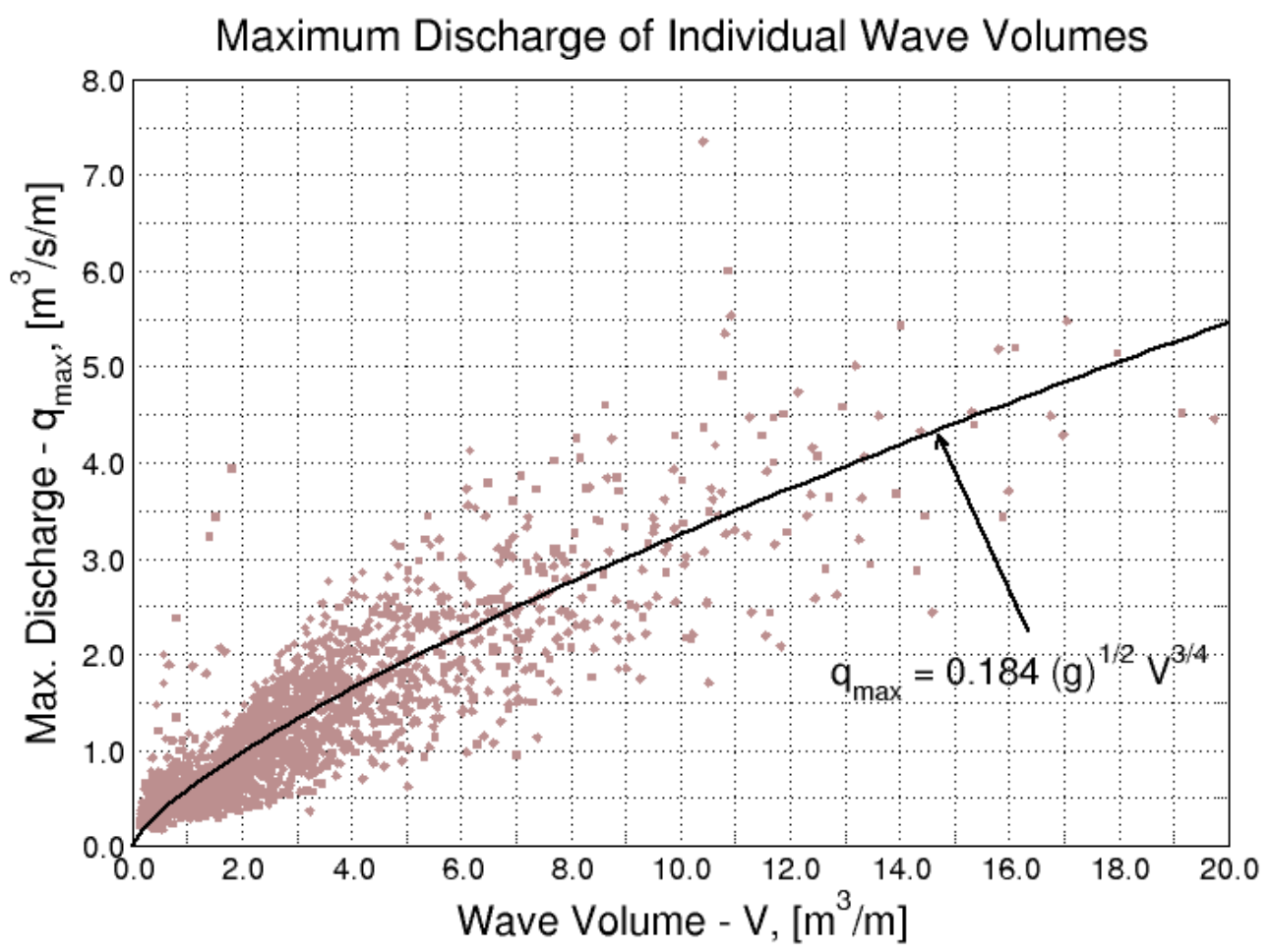

Figure 10. Values of maximum discharge $\left(q_{\max }\right)$ versus individual wave volume.

\section{Shape of Individual Overtopping Waves}

Hughes (2011) suggested simplified analytical power-curve forms for the instantaneous flow thickness and velocity in individual overtopping waves given by the expressions

$$
h(t)=h_{\max }\left[1-\frac{t}{T_{o}}\right]^{a} \quad \text { for } 0 \leq t \leq T_{0}
$$

and

$$
u(t)=U_{\max }\left[1-\frac{t}{T_{o}}\right]^{b} \quad \text { for } 0 \leq t \leq T_{0}
$$

When the exponents $a$ and $b$ are unity, the decreases in flow thickness and velocity are linear (which turns out to be a reasonable assumption). Combining Eqs. 17 and 18 gives the individual wave volumetric discharge per unit levee length (assuming $h_{\max }$ and $U_{\max }$ occur at the same location), i.e.,

$q(t)=h_{\max } U_{\max }\left[1-\frac{t}{T_{o}}\right]^{a+b}=q_{\max }\left[1-\frac{t}{T_{o}}\right]^{m}$ for $0 \leq t \leq T_{0}$

where the product of the peak flow thickness and peak velocity has been replaced with the peak discharge, $q_{\max }$, and the exponent, $m=a+b$. The volume (per unit levee length) of the individual overtopping wave is simply the integration of the discharge hydrograph with respect to time, or 
$V=\int_{0}^{T_{0}} q(t) d t=\int_{0}^{T_{0}} q_{\max }\left[1-\frac{t}{T_{0}}\right]^{m} d t=\frac{q_{\max }}{\left(T_{o}\right)^{m}} \int_{0}^{T_{0}}\left[T_{o}-t\right]^{m} d t$

Carrying out the integration and evaluating at the limits yields

$$
V=\frac{q_{\max }}{\left(T_{o}\right)^{m}}\left[\frac{\left(T_{o}-t\right)^{m+1}}{(m+1)(-1)}\right]_{0}^{T_{o}}=\frac{q_{\max }\left(T_{o}\right)^{m+1}}{(m+1)\left(T_{o}\right)^{m}}
$$

or

$$
V=\frac{q_{\max } T_{o}}{(m+1)}
$$

which is a simple expression for individual wave volume as a function of peak discharge, overtopping duration, and the unknown factor, $m$.

The product of maximum discharge and overtopping duration is plotted against individual wave volume for all nine experiments in Fig. 11. The best-fit to the data was a dimensionally nonhomogeneous equation (coefficient has units!) given by

$$
V^{1.16}=0.43\left(q_{\max } T_{o}\right)
$$

where $V$ has units of $\mathrm{m}^{3} / \mathrm{m}, q_{\max }$ has units of $\mathrm{m}^{3} / \mathrm{s}$ per $\mathrm{m}$, and $T_{o}$ has units of seconds. Rearranging Eq. 23 into the same form as Eq. 22 gives the expression

$$
V=\frac{q_{\max } T_{o}}{2.33 V^{0.16}}
$$

which implies that the exponent $m$ in Eq. 19 is a function of overtopping wave volume, i.e.,

$$
m=a+b=2.33 V^{0.16}-1
$$

Equation 25 suggests that the discharge shape becomes more concave with increasing wave volume, i.e., the exponent $m$ increases. Physically, this might be interpreted as follows. When smaller volumes overtop, most of the forward wave momentum is exhausted on the seaward slope. However, when large volumes overtop, more of the forward momentum is carried over onto the levee crest. Because momentum is related to velocity, it is feasible that the time-varying wave velocity (Eq. 18) is more concave which means the exponent $b$ in Eq. 19 is larger for large overtopping wave volumes.

\section{Individual Wave Overtopping Duration}

Based on the correlations shown in Figs. 10 and 11, an expression can be derived for the overtopping duration $\left(T_{o}\right)$ of individual wave volumes. Solving Eq. 23 for $q_{\max }$ and equating to Eq. 16 yield the following dimensionally non-homogenous equation

$$
T_{o}=4.0 V^{0.41}
$$

where $T_{o}$ has units of seconds, $V$ has units of $\mathrm{m}^{3} / \mathrm{m}$, and $g=9.8146 \mathrm{~m} / \mathrm{s}^{2}$ in Eq. 16 . Equation 26 is shown on Fig. 12 along with the scatter plot of nearly 2,100 data pairs extracted from the measured data. The wide scatter indicates some of the uncertainty in determining actual overtopping duration from measured data, but the derived equation gives a reasonable trend. A best-fit two-parameter power curve to the data gave a similar expression, $T_{o}=3.9 V^{0.46}$. 


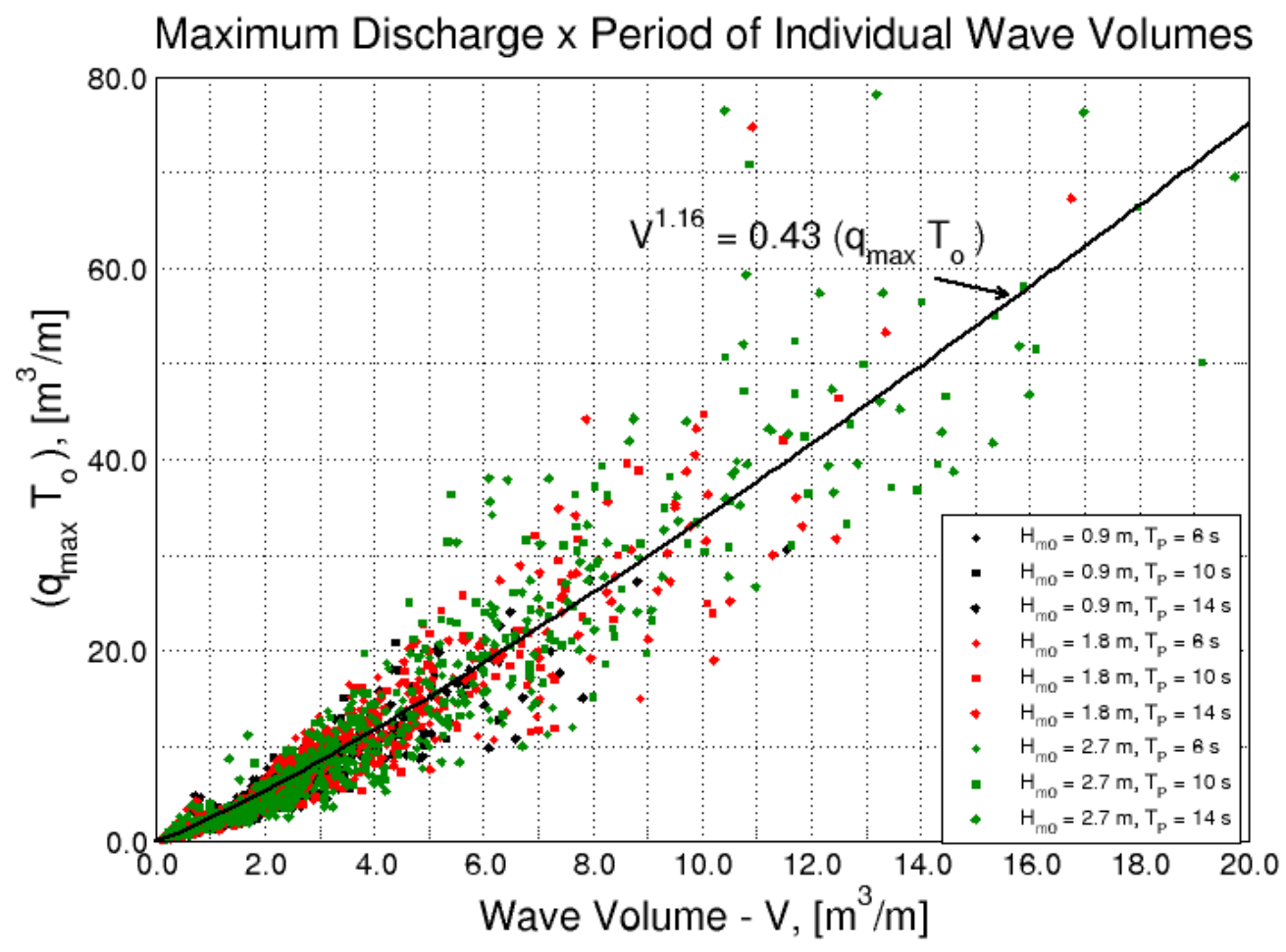

Figure 11. Values of $\left(q_{\max } T_{o}\right)$ versus individual wave volume.

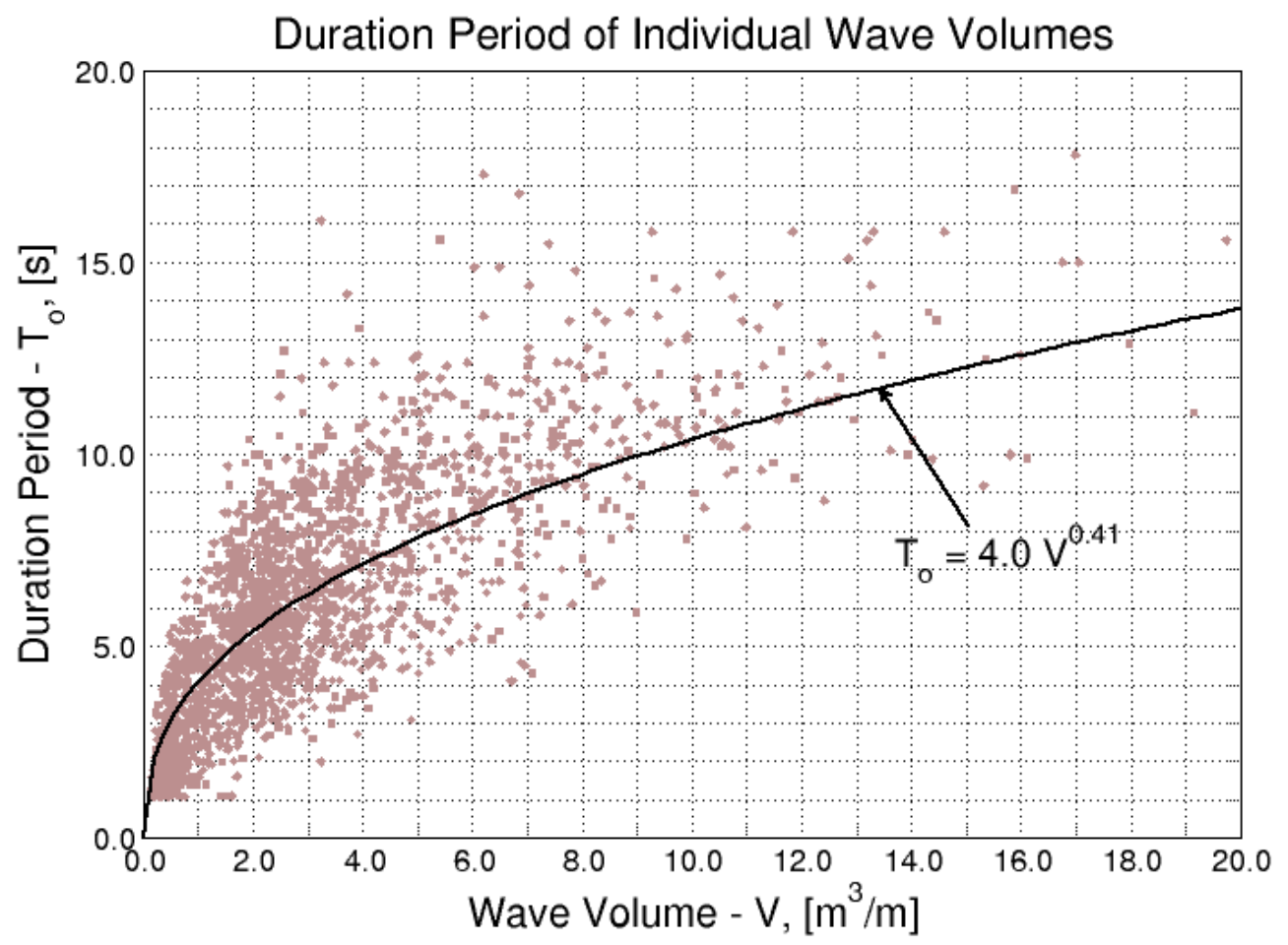

Figure 12. Overtopping duration $T_{o}$ versus individual wave volume. 


\section{SUMMARY}

Improved estimation of wave overtopping parameters provides engineers with better tools for designing resilient levees and dikes, including the full-scale simulation of wave overtopping. The Weibull distribution has been shown to give accurate estimation of the distribution of wave overtopping volumes. However, the shape parameter of the Weibull distribution was determined for relatively low values of average overtopping discharge. New small-scale measurements by Victor, et al. (2012), and reanalysis of the small-scale combined wave and surge overtopping of Hughes and Nadal (2009), resulted in an improved empirical formula for the Weibull distribution shape that spans the range from low overtopping with positive freeboards to huge overtopping with negative freeboards. The maximum wave volume estimated from the new distribution is smaller than previously thought, and this allows fix-volume wave overtopping simulators to reproduce larger average discharges before reaching the wave simulator's upper limit.

Hydrodynamic parameters of individual overtopping wave volumes were examined using data from nine tests of combined wave overtopping and steady surge overflow having negative freeboard of $R_{c}=0.29 \mathrm{~m}$ (prototype equivalent). Analyses of maximum instantaneous flow thickness, velocity, and discharge of individual wave volumes suggested that these maximum parameters follow the Rayleigh distribution to some degree. An important finding was that the $2 \%$-exceedance values for flow thickness and velocity do not occur in the same wave volume, and they do not occur in the $2 \%$ exceedance wave volume. This complicates specifying maximum flow thickness and velocity as a function of wave volume.

The combined wave overtopping data were used to determine empirical equations for maximum instantaneous discharge $\left(q_{\max }\right)$ and overtopping duration $\left(T_{o}\right)$ as a function of individual wave volume. However, caution is urged before utilizing these equations because there was significant scatter about the central trends, and the data used to establish the equations represent an extreme case relative to wave-only overtopping.

The shape of the overtopping wave volume, as represented by the instantaneous discharge, appears to become more concave for larger overtopping volumes. It was hypothesized that this change in the discharge shape is caused by a greater amount of forward wave momentum overtopping the levee crest.

This study has provided some improvements to the description of the wave overtopping physical process, but it is still apparent that additional research is needed to characterize individual overtopping waves more accurately.

\section{Acknowledgments}

The data of Hughes and Nadel were originally obtained in experiments funded by the New Orleans District of the U.S. Army Corps of Engineers. A special thanks to Lander Victor and Peter Troch for providing analyzed Weibull shape factor values from their 364 experiments.

\section{REFERENCES}

Hughes, S. A. 2011. Adaptation of the levee erosional equivalence method for the Hurricane Storm Damage Risk Reduction System (HSDRRS)," ERDC/CHL TR-11-3, U.S. Army Engineer Research and Development Center, Vicksburg, Mississippi, 143pp.

Hughes, S. A., and Nadal, N. C. 2009. Laboratory study of combined wave overtopping and storm surge overflow of a levee, Coastal Engineering, Elsevier, Vol 56. No. 3, pp 244-259.

Lorke, S., Brüning, A., Bornschein, A., Gilli, S., Krüger, N., Schüttrumpf, H., Pohl, R., Spano, M., and Werk, S. 2010a. Influence of wind and current on wave run-up and wave overtopping, Hydralab - FlowDike, Report 2009, 100pp.

Lorke, S., Brüning, A., Van der Meer, J. W., Schüttrumpf, H., Bornschein, A., Gilli, S., Pohl, R., Spano, M., Riha, J., Werk, S., and Schlütter, F. 2010b. On the effect of current on wave run-up and wave overtopping. Proceedings of the 32st International Conference Coastal Engineering, American Society of Civil Engineers. Available at: http://journals.tdl.org/ICCE/article/view/1388. 
Schüttrumpf, H., Möller, J., and Oumeraci, H. 2002. Overtopping flow parameters on the inner slope of seadikes, Proceedings of the 28th International Coastal Engineering Conference, World Scientific, Vol 2, pp 2116-2127.

Schüttrumpf, H., and Oumeraci, H. 2005. Layer thicknesses and velocities of wave overtopping flow at seadikes, Coastal Engineering, Elsevier, Vol 52, pp 473-495.

Van der Meer, J. W. 2010. Operating system of the US wave overtopping simulator, Manual, Van der Meer Consulting B.W., The Netherlands, 53pp.

Van der Meer, J. W., Snijders, W., and Regeling, E. 2006. The wave overtopping simulator, Proceedings of the 30th International Conference Coastal Engineering, American Society of Civil Engineers, Vol 5, pp. 4654-4666.

Van der Meer, J. W., Steendam, G. J., de Raat, G., and Bernardini, P. 2008. Further developments on the wave overtopping simulator, Proceedings of the 31st International Conference Coastal Engineering, American Society of Civil Engineers, Vol 4, pp. 2957-2969.

Van der Meer, J. W., and Janssen, W. 1995. Wave run-up and wave overtopping at dikes, In: Kabayashi and Demirbilek (Eds.), Wave Forces on Inclined and Vertical Wall Structures, American Society of Civil Engineers, pp 1-27.

Van der Meer, J. W., Hardeman, B., Steendam, G. J., Schüttrumpf, H., and Verheij, H. 2010. Flow depths and velocities at crest and inner slope of a dike, in theory and with the wave overtopping simulator, Proceedings of the 32st International Conference Coastal Engineering, American Society of Civil Engineers. Available at: http://journals.tdl.org/ICCE/article/view/1239.

Van Gent, M. R. 2002. Wave overtopping events at dikes, Proceedings of the 28th International Coastal Engineering Conference, World Scientific, Vol 2, pp 2203-2215.

Victor, L. 2012. Optimization of the hydrodynamic performance of overtopping wave energy converters: experimental study of optimal geometry and probability distribution of overtopping volumes, $\mathrm{PhD}$ dissertation, Department of Civil Engineering, Ghent University, Belgium.

Victor, L., Van der Meer, J. W., and Troch P. 2012. Probability distribution of individual wave overtopping volumes for smooth impermeable steep slopes with low crest freeboard, Coastal Engineering, Elsevier, Vol 64, pp 87-101. 